\title{
Histopathological Study of Radicular Cysts Diagnosed in a Brazilian Population
}

\author{
Luciano Cincurá Silva Santos ${ }^{1}$ \\ Deise Souza Vilas Bôas ${ }^{2}$ \\ Gabriel Queiroz Vasconcelos Oliveira ${ }^{1}$ \\ Eduardo Antônio Gonçalves Ramos ${ }^{3}$ \\ Clarissa Araújo Silva Gurgel ${ }^{1}$ \\ Jean Nunes dos Santos ${ }^{1}$
}

\begin{abstract}
${ }^{1}$ Laboratory of Oral Surgical Pathology, Dental School, UFBA - Federal University of Bahia, Salvador, BA, Brazil ${ }^{2}$ Department of Bio-Morphology, Institute of Health Sciences, UFBA - Federal University of Bahia, Salvador, BA, Brazil

${ }^{3}$ Laboratory of Histopathology, Gonçalo Moniz Research Center, Oswaldo Cruz Foundation, Salvador, BA, Brazil
\end{abstract}

\begin{abstract}
The aim of this study was to investigate the histopathological features of radicular cysts (RCs) diagnosed in a Brazilian population. Seventy-three cases of RCs, from a total of 1480 biopsies diagnosed between 2001 and 2008 at the Laboratory of Oral Surgical Pathology of the Dental School of the Federal University of Bahia were investigated regarding their histopathological features. Morphological results showed that exocytosis $(n=50)$, spongiosis $(n=40)$, acanthosis $(n=28)$, atrophic epithelium $(n=27)$ and apoptotic bodies $(n=21)$ were the most common findings. Other morphological findings included: foamy macrophages ( $n=10)$, Russell's bodies $(\mathrm{n}=7)$, cholesterol crystals $(\mathrm{n}=7)$ and glandular-like odontogenic epithelial rests $(\mathrm{n}=1)$. Evidence of exogenous material was seen in 16 samples. It was concluded that the clinical and histopathological findings observed in Brazilian patients were comparable with those described for other populations.
\end{abstract}

Key Words: Odontogenic cysts, histopathology, radicular cyst.

\section{INTRODUCTION}

Radicular cysts (RCs) are the most common cysts affecting the jawbones. They are related to extensive caries lesions, pulp necrosis and infection of the root canal (1). RCs arise to control the infection as the lowintensity chronic stimulus triggered by bacterias and their products provides conditions to the organism, confining the aggression to the periapical region. During these events of defense, different cells produce cytokines, mainly interleukin 1 (IL-1), IL-6 and tumor necrosis factor alpha (TNF- $\alpha$ ), which are involved in this immunoinflammatory response and play a role in bone resorption and in the stimulation of mitogenesis (2). In addition, foreign body-type material and other morphological findings might be observed in RCs, either potentiating the inflammatory process $(3,4)$ or as a result of the defensive mechanism of the organism itself.

Histopathologically, RCs consist of a cavity lined by stratified squamous epithelium exhibiting spongiosis and/or exocytosis and are delimited by a fibrous wall containing a predominantly chronic inflammatory infiltrate (1). However, little has been described about the histopathological features and variations of RCs diagnosed in Brazilian individuals specifically. Thus, the aim of the present study was to describe the histopathological features and possible variations of $\mathrm{RCs}$ in a Brazilian population.

\section{MATERIAL AND METHODS}

After approval from the Ethics Committee of the Federal University of Bahia, 73 cases diagnosed as RCs were included in the study sample. This accounted for $4.9 \%$ out of 1,480 biopsies performed at the Laboratory of Surgical Pathology of the Dental School of the Federal University of Bahia, between 2001 and 2008.

The formalin-fixed, paraffin-embedded material

Correspondence: Dr. Jean Nunes dos Santos, Avenida Araújo Pinho, 62, Canela, 40110-150 Salvador, BA, Brasil. Tel: +55-71-3283-9019. Fax: +55-71-3283-8962. e-mail: jeanunes@ufba.br 
was cut into 4- $\mu \mathrm{m}$ thick sections for morphological analysis. After staining with hematoxylin-eosin, the slides were revised by one experienced pathologist (J.N.S) who recorded the representative histopathological features of each lesion. The criterion used to name the lesions of radicular cyst was a well-delimited cavity lined by stratified squamous epithelium defined by Nair (1). The inflammatory infiltrate was classified as discrete, moderate or intense, and the epithelium was classified as atrophic ( 2 to 10 cell layers) or hyperplastic ( $>10$ cell layers) (5). Furthermore, other morphological features as apoptosis, mucosal cells, odontogenic epithelial remnants, eosinophilic bodies of Rushton, foamy macrophages, cholesterol crystals, and others were also included. Data regarding the gross pathology as size and

Table 1. Distribution of morphological alterations observed in radicular cysts from the pathology archives of the Dental School of the Federal University of Bahia, diagnosed between 2001 and 2008 (Salvador, BA, 2009).

\begin{tabular}{lc}
\hline Morphological aspects & $\mathrm{n}$ \\
\hline Stratified squamous epithelium & 73 \\
Exocytosis & 50 \\
Spongiosis & 40 \\
Acanthosis & 28 \\
Atrophic epithelium & 27 \\
Apoptotic bodies & 21 \\
Hemorrhage & 18 \\
Exogenous material & 16 \\
Vacuolized cells & 14 \\
Multinucleate giant cells & 13 \\
Odontogenic epithelial rests & 11 \\
Foamy macrophages & 10 \\
Rushton bodies & 7 \\
Mucosal cells & 7 \\
Cholesterol crystals & 3 \\
Russell bodies & 7 \\
Simple cuboidal epithelium & 7 \\
Epithelial plaques resembling squamous & 3 \\
odontogenic tumors & \\
Pseudostratified ciliated epithelium & 7 \\
\hline & \\
\hline
\end{tabular}

cystic aspect were also obtained.

Differences between groups were evaluated using Fisher's exact and Kruskal-Wallis tests. All statistical calculations were performed using the GraphPad Prism 4.0 program (GraphPad Inc., San Diego, CA, USA). A p-value $<0.05$ was considered to be statistically significant.

\section{RESULTS}

The histopathological findings are summarized in Table 1. Most lesions (69\%) presented as a cystic formation by the gross pathology. The diameter of the cysts ranged from 0.5 to $7.6 \mathrm{~cm}$, with a mean size of $1.94 \mathrm{~cm}$ (Fig. 1A,B). No information regarding the latter aspect was available in one case.

The 73 lesions selected fulfilled the morphological criteria for RCs, but they exhibited different histological characteristics. These lesions generally presented as cystic formations consisting of a fibrous wall lined by stratified pavement epithelium arranged in interconnecting rings. The epithelium was hyperplastic in $28(38.4 \%)$ cases and atrophic in $27(37 \%)$. Exocytosis was observed in $50(68.5 \%)$ cases and spongiosis in 40 (54.8\%), often accompanied by apoptotic bodies $(\mathrm{n}=21$, $28.8 \%$ ) and Rushton bodies ( $\mathrm{n}=7,9.6 \%)$. Other types of epithelial lining were also observed, including simple

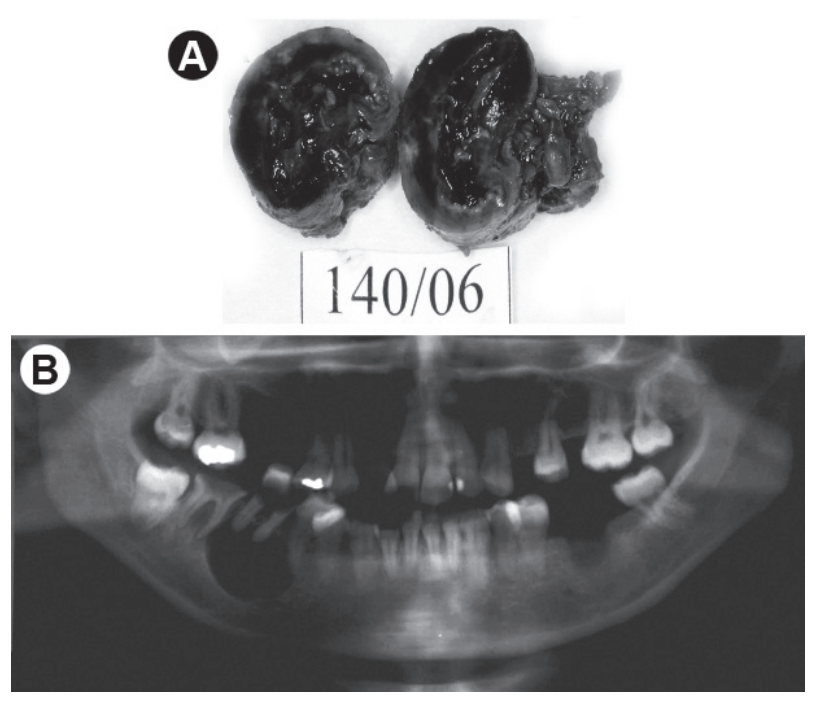

Figure 1. Radicular cyst. $\mathrm{A}=$ Gross pathology showing a circumscribed and encapsulated lesion, measuring $2.5 \times 2.2 \times 2.0$ $\mathrm{cm}$. The cut surface was cystic and filled with hemorrhagic content. Small protuberances can also be seen in the inner side of the cyst wall. $\mathrm{B}=$ Panoramic radiograph showing a large radiolucency circumscribed on the periapex of the mandibular right first molar. 
cuboidal epithelium $(n=3,4.1 \%)$ and pseudostratified ciliated epithelium $(n=3,4.1 \%)$. Mucosal cells were identified in seven $(9.6 \%)$ cases and vacuolized cells in $14(19.2 \%)$.

Odontogenic epithelial rests were present in 11 $(15.1 \%)$ cases, with the observation of glandular-like odontogenic epithelial rests in one case $(1.4 \%)$ and of an island of degenerating odontogenic epithelium in another (1.4\%). Epithelial plaques resembling squamous odontogenic tumors were observed in three (4.1\%) cases. Foamy macrophages and cholesterol crystals were seen in $10(13.7 \%)$ and seven $(9.6 \%)$ cases, respectively. Other features observed included hemorrhage, interstitial edema, exogenous material, Russell bodies and multinucleate giant cells (Table 1 and Figs. 2 and 3).

Statistical analysis was performed to determine
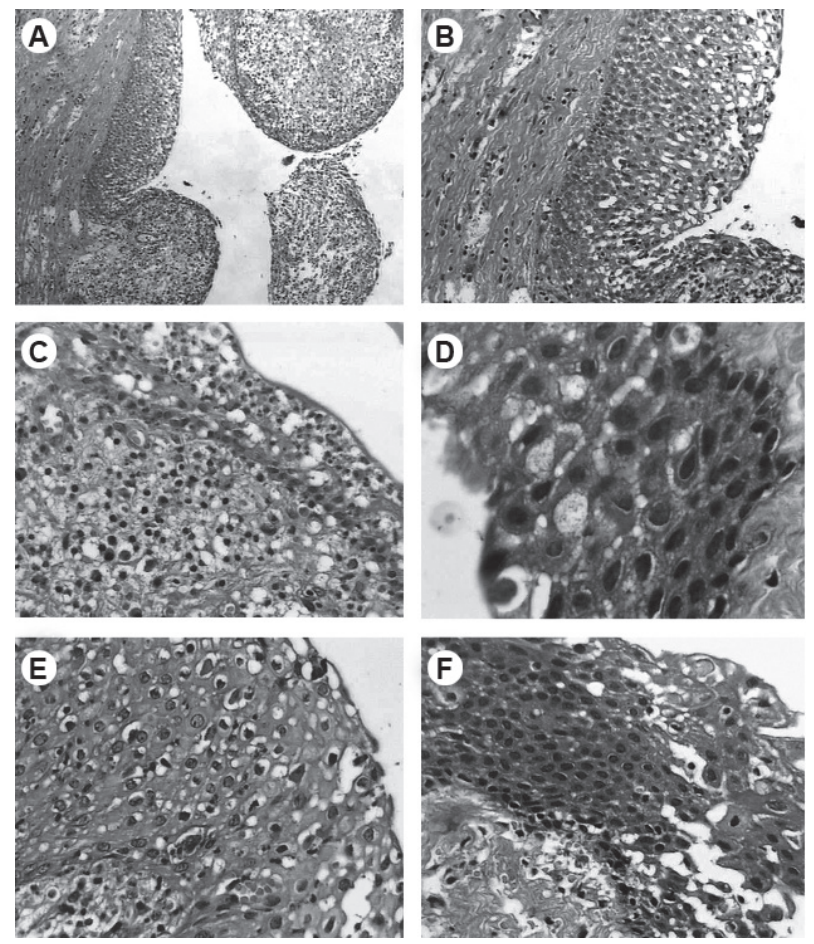

Figure 2. Radicular Cyst. A = Cystic wall covered by stratified pavement epithelium arranged in interconnecting rings and exhibiting chronic inflammation; $\mathrm{B}=$ Cystic lining with hyperplasia and exocytosis of leukocytes; $\mathrm{C}=$ Cystic wall covered by epithelium showing atrophy and strong exocytosis of leukocytes, and chronic inflammation; D = Mucosal and vacuolized cells beside squamous cells; $\mathrm{E}=$ Apoptotic cells exhibiting eosinophilic cytoplasm and nuclear condensation; $\mathrm{F}=$ Squamous epithelium exhibiting metaplastic cells close to cystic lumen. a possible influence of these histological findings on the occurrence of RC. Comparison of the presence of exogenous material and epithelial thickness showed that among the 16 cases presenting exogenous material, 10 exhibited an atrophic epithelium and 6 a hyperplastic epithelium, with no significant difference between groups (Fisher's test, $\mathrm{p}=0.2448$ ). No significant association between exogenous material and the degree of inflammation was observed (Kruskal-Wallis test, $\mathrm{p}=0.6514$ ). A significant positive association was observed between the presence of Rushton bodies and apoptotic cells, with Rushton bodies being detected in 5 of the 21 cases presenting apoptotic cells (Fisher's test, $\mathrm{p}=0.0014$ ). However, no significant association was observed between the presence of apoptotic cells and epithelial thickness (Fisher's test, $\mathrm{p}=0.2695$ ).

Analysis of the concomitant presence of foamy macrophages and cholesterol crystals in the same cyst revealed no significant association between these structures, with only one specimen containing
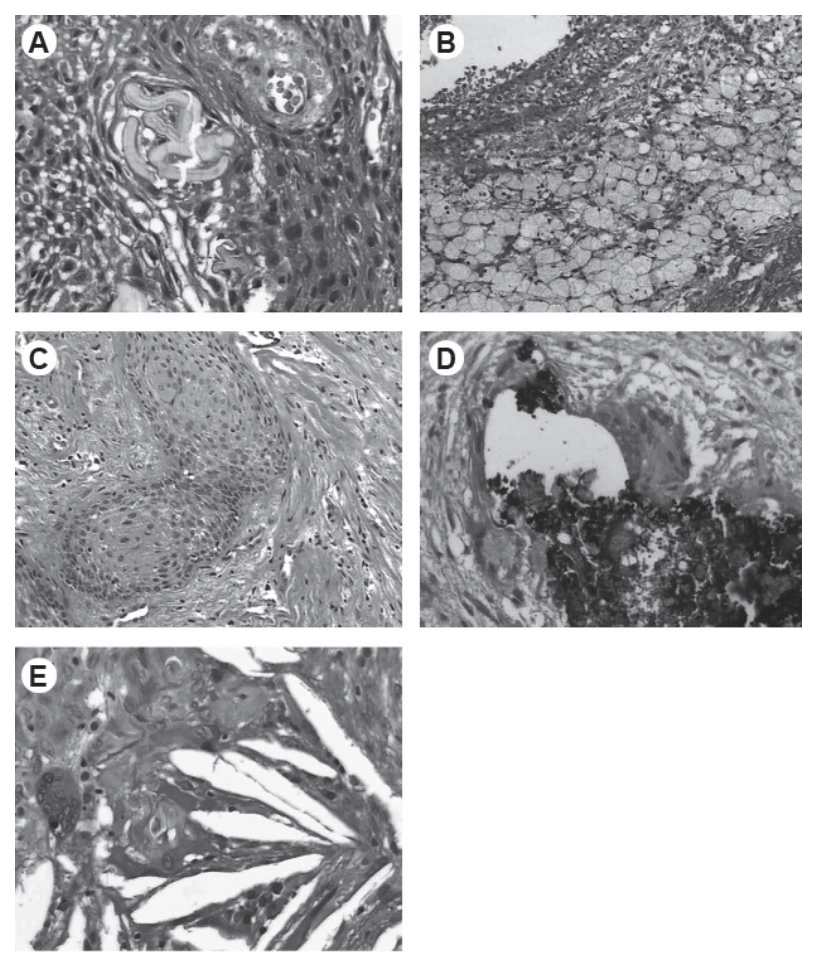

Figure 3. Radicular Cyst. A=Hyaline bodies of Rushton composed of lamellar structures surrounded by epithelial cells; B = Cystic wall showing marked accumulation of foamy macrophages; $\mathrm{C}$ $=$ Epithelial remnants resembling squamous odontogenic tumorlike; $\mathrm{D}=$ Exogenous material and foreign body reaction with multinucleated giant cells and focal calcification; $\mathrm{E}=$ Cholesterol crystals and foreign body-type reaction with giant cells. 
foamy macrophages out of 10 cases, in addition to the cholesterol crystals (Fisher's test, $\mathrm{p}=0.9507$ ).

The inflammatory infiltrate observed in the sample was mainly chronic. This infiltrate was intense in 36 cases $(49.3 \%)$, discrete in $22(30.1 \%)$ and moderate in $15(20.5 \%)$. Acute inflammation characterized by the presence of neutrophils was observed in 7 cases, and the infiltrate was mixed in 2 cases.

\section{DISCUSSION}

According to previous studies, RCs accounts for $6 \%$ to $57.69 \%$ of all periapical lesions $(6,7)$. This variation might be attributed to differences in the definition of this type of cyst.

The mean diameter of the cysts studied here was $1.94 \mathrm{~cm}$, a value similar to those reported by previous studies, although exists variation (1). Histologically, the lesions fulfilled the criteria adopted for radicular cysts (1). They consisted of a cystic wall lined by stratified nonkeratinized squamous epithelium, sometimes arranged in often interconnecting rings, which exhibited spongiosis and exocytosis and was hyperplastic or atrophic. Chronic inflammatory infiltrate, multinucleated giant cells and neutrophils were also observed in the cysts. These features are comparable to those described previously $(1,5)$.

Ciliated epithelia is uncommon in radicular cyst $(7,8)$. In this study, pseudostratified ciliated epithelium was exclusively observed in RCs located in the anterior region of the maxilla. Similar findings also were identified by Takeda et al. (8) and Nair et al. (9). This might be attributed to a possible metaplasia of stratified squamous epithelium as a consequence of the presence of remnant respiratory tissues during embryogenesis $(8,9)$. Another explanation might be attributed to the inflammatory stimulation on the stratified squamous epithelium that differentiates by metaplasia into ciliated columnar epithelium (1). This event is influenced by the presence of fluids inside the cavity. However, the biological significance of this phenomenon remains unknown.

In the present study, 2 out of 3 cases exhibiting a ciliated epithelium also presented mucosal cells (8). These cells were only detected in 7 cases of this series. The frequency of mucosal cells $(86 \%)$ and ciliated cells $(100 \%)$ was higher in the maxilla. The occurrence of mucosal cells in odontogenic cysts is probably also due to a metaplastic phenomenon $(8,10)$. Slabbert et al. (10) demonstrated the presence of vacuolized cells in almost $10 \%$ of their series. In contrast, in the present study was observed vacuolized cells in almost $20 \%$ of the samples. These cells were associated with mucosal cells scattered or in clusters throughout the layers of the stratified pavement epithelium, except for the basal layer (10).

Apoptosis is a mechanism of genetically programmed cell death which plays an important role in the control of cell populations (11). This study showed apoptotic cells in almost $30 \%$ of the cases. In contrast, Loyola et al. (10) detected these cells in all of their cases exhibiting mainly atrophic epithelium, by using bcl-2 immunostaining. However, Suzuki et al. (11), using p53, Bax, caspase-3, Fas and Fas-L, concluded that both proliferative activity and apoptosis are more frequent in RCs exhibiting a thick epithelium. This finding is in agreement with the present results as apoptotic cells were seen in most lesions containing a hyperplastic epithelium. However, this association was not significant.

Rushton bodies or hyaline bodies exhibiting a wide variety of shapes, including linear, round, lamellar or amorphous structures, were found in the epithelium of RCs $(13,14)$. The presence of these structures depends on the sectioning plane of the material, with their incidence ranging from $2.6 \%$ to $10.3 \%$. In the present study, Rushton bodies were detected in few RCS. They presented a lamellar shape without calcifications. The origin of hyaline bodies has not been well established. However, it is known that hyaline bodies result from the entrapment of blood vessels by the epithelium and consequent vessel thrombosis. Another hypothesis is that cell debris or cholesterol crystals present in the cyst might stimulate epithelial cells to secrete amorphous substances that later undergo to calcification, originating Rushton bodies (13). Despite these hypotheses, Pesce and Ferloni (14) and Loro et al. (15) suggested that these structures are formed by apoptosis of epithelial cells accompanied by intracellular dystrophic calcification. It is important to comment that Loyola et al. (11), studying apoptosis in RCs, did not observe the presence of hyaline bodies. Further studies are necessary to better understand the presence of these structures in RCs.

In the present study, odontogenic epithelial rests were detected in some cases. Although the role of epithelial rests of Malassez is unclear, it has been suggested that they are associated with tissue remodeling and to exert reparative functions such as the prevention of ankylosis, maintenance of the periodontal space and prevention of root surface resorption $(16,17)$. In 
addition, we observed epithelial plaques resembling squamous odontogenic tumor (18). The odontogenic epithelium seems to have a potential for proliferation and differentiation into squamous cells, and also participates in tooth formation. However, it is still unknown which event is involved in the formation of this squamous odontogenic tumor-like epithelial tissue. Thus, it could be recommended that cystic lesions containing squamous odontogenic tumor-like epithelial plaques to be followed up for a longer period of time as signs and symptoms of the tumor are only detectable in advanced stages of the disease.

In agreement with other studies, lymphocytes and plasma cells were found associated with the fibrous capsule in the present investigation (6). The intensity of the inflammatory infiltrate varied, but intense inflammation was predominant. In RCs, the degree of inflammation might be associated with the proliferative activity of their epithelial cells (11).

Russell bodies also were present in several cases. These bodies are formed by the accumulation of immunoglobulins in endoplasmic reticulum cisterns found in chronically inflamed tissue (19). It is essential to recognize these structures, as described in a recent report on periapical lesion rich in Russell bodies and plasma cells, mimicking a malignant neoplasm (19).

Macrophages are involved in the innate response of the periapical lesion, phagocytosing bacteria and preventing the dissemination of infection, as well as in the acquired response, presenting antigens to lymphocytes through the MHC II system, synthesizing cytokines and producing metalloproteinases (20). These defense cells may also phagocytose cholesterol crystals and are called foamy macrophages $(3,4,21)$. However, phagocytosis may not occur in the presence of some crystals exhibiting a large diameter, an event that induces the release of cytokines such as IL-1, impairing the repair process after endodontic treatment (3,6,20-23). Thus, the presence of cholesterol crystals is an important factor for lesion persistence (3,4,20-22). These crystals may originate from the crystallization of lipids ingested from the vascular system itself, or may result from the production of local metabolites in the granulation tissue of the cystic wall and from the phagocytosis of the cell membranes of dead cells (21).

Extensive clusters of foamy macrophages are rare in endodontic lesions and, when present in large numbers, are suggestive of a proliferative process or a localized bone reaction. Periapical lesions exhibiting an abundance of these cells seem to be more aggressive and are associated with a larger number or recurrences even after correct conventional endodontic treatment, with these lesions often being treated by paraendodontic surgery (24). Foamy macrophages were observed in few cases of the present series, sometimes side by side with cholesterol crystals. However, no significant correlation was found between the presence of foamy macrophages and cholesterol crystals in RCs. This finding might be attributed to the fact that foamy macrophages already phagocytosed small lipid accumulations before the formation of larger crystals.

Exogenous material compatible with endodontic filling material was also observed close to the mineralization foci and foreign body-type reactions (25). The latter was also observed in the present study. Foreign body reactions occur concomitantly with intense inflammatory infiltrates containing macrophages and multinucleated giant cells (23). In addition, an intense inflammatory infiltrate was observed in $50 \%$ of cysts containing exogenous material, but comparison between the presence of this material and the different intensities of inflammatory infiltration showed no significant association. Analysis of the presence of exogenous material and epithelial thickness showed that among the cystic lesions containing exogenous material, most were characterized by the presence of an atrophic epithelium, whereas $37.5 \%$ presented a hyperplastic epithelium, with no significant difference between groups. Possibly, conventional endodontic treatment reduced the immunoinflammatory reactions in these cysts and, consequently, the power of cytokines and other substances involved in epithelial proliferation.

Finally, the present results revealed that RCs may show distinct histopathological findings in the same lesion, and this provides an important insight into the knowledge of the morphological variations of RCs. Based on the present study, it may be concluded that the clinical and histopathological findings observed in Brazilian patients were comparable with those described for other populations.

\section{RESUMO}

O propósito desse estudo foi investigar os aspectos histopatológicos de cistos radiculares diagnosticados em uma população brasileira. Setenta e três casos de cistos radiculares entre 1480 biópsias diagnosticadas na Faculdade de Odontologia da Universidade Federal da Bahia, entre 2001 e 2008, foram investigados, considerando os seus aspectos histopatológicos. Os resultados 
morfológicos mostraram que os achados mais comuns foram a exocitose $(n=50)$, espongiose $(n=40)$, acantose $(n=28)$, epitélio atrófico $(n=27)$ e células apoptóticas $(n=21)$. Outros achados encontrados incluíram macrófagos espumosos $(\mathrm{n}=10)$, corpúsculos de Russell $(n=7)$, imagens negativas de colesterol $(n=7)$ e restos epiteliais odontogênicos semelhantes à tecido glandular $(n=1)$. Material exógeno foi observado em 16 casos. Concluiu-se que os aspectos histopatológicos e clínicos observados foram comparáveis a outros descritos em outras populações.

\section{REFERENCES}

1. Nair PN. New perspectives on radicular cysts: do they heal? Int Endod J 1998;31:155-160.

2 Meghji S, Qureshi W, Henderson B, Harris M. The role of endotoxin and cytokines in the pathogenesis of odontogenic cysts. Arch Oral Biol 1996;41:523-531.

3. Sjögren U, Mukohyama H, Roth C, Sundqvist G, Lerner UH. Bone-resorbing activity from cholesterol-exposed macrophages due to enhanced expression of interleukin-1alpha. J Dent Res 2002;81:11-16.

4. Yamazaki M, Cheng J, Hao N, Takagi R, Jimi S, Itabe H, et al. Basement membrane-type heparan sulfate proteoglycan (perlecan) and low-density lipoprotein (LDL) are co-localized in granulation tissues: a possible pathogenesis of cholesterol granulomas in jaw cysts. J Oral Pathol Med 2004;33:177-184.

5. Moreira PR, Santos DF, Martins RD, Gomez RS. CD57+ cells in radicular cyst. Int Endod J 2000;33:99-102.

6. Ricucci D, Pascon EA, Ford TR, Langeland K. Epithelium and bacteria in periapical lesions. Oral Surg Oral Med Oral Pathol Oral Radiol Endod 2006;101:239-249.

7. Sharifian MJ, Khalili M. Odontogenic cysts: a retrospective study of 1227 cases in an Iranian population from 1987 to 2007 . J Oral Sci 2011;53:361-367.

8. Takeda Y, Oikawa Y, Furuya I, Satoh M, Yamamoto H. Mucous and ciliated cell metaplasia in epithelial linings of odontogenic inflammatory and developmental cysts. J Oral Sci 2005;47:77-81.

9. Nair PN, Pajarola G, Luder HU. Ciliated epithelium-lined radicular cysts. Oral Surg Oral Med Oral Pathol Oral Radiol Endod 2002;94:485-493.

10. Slabbert H, Shear M, Altini M. Vacuolated cells and mucous metaplasia in the epithelial linings of radicular and residual cysts. J Oral Pathol Med 1995;24:309-312.

11. Loyola AM, Cardoso SV, Lisa GS, Oliveira LJ, Mesquita RA, Carmo MA, et al.. Apoptosis in epithelial cells of apical radicular cysts. Int Endod J 2005;38:465-469.
12. Suzuki T, KumamotoH, KunimoriK, Ooya K. Immunohistochemical analysis of apoptosis-related factors in lining epithelium of radicular cysts. J Oral Pathol Med 2005;34:46-52.

13. Cohen M. A review of Rushton hyaline bodies. Diastema 1976;4:30-36.

14. Pesce C, Ferloni M. Apoptosis and Rushton body formation. Histopathology 2002;40:109-111.

15. Loro L, Vintermyr OK, Johannessen AC. Apoptosis in normal and diseased oral tissues. Oral Dis 2005;11:274-287.

16. Nickolaychuk B, McNicol A, Gilchrist J, Birek C. Evidence for a role of mitogen-activated protein kinases in proliferating and differentiating odontogenic epithelia of inflammatory and developmental cysts. Oral Surg Oral Med Oral Pathol Oral Radiol Endod 2002;93:720-729.

17. Götz W, Lossdörfer S, Krüger U, Braumann B, Jäger A. Immunohistochemical localization of insulin-like growth factor-II and its binding protein- 6 in human epithelial cells of Malassez. Eur J Oral Sci 2003;111:26-33.

18. Olivera JA, Costa IM, Loyola AM. Squamous odontogenic tumor-like proliferation in residual cyst: a case report. Braz Dent J 1995;6:59-64.

19. Dos Santos JN, Ramos EA, Gurgel CA, Barros AC, de Freitas AC, Crusoé-Rebello IM. Russell body apical periodontitis: an unusual case report. Oral Surg Oral Med Oral Pathol Oral Radiol Endod 2008;106:903-908.

20. Metzger Z. Macrophages in periapical lesions. Endod Dent Traumatol 2000;16:1-8.

21. Nair PN, Sjögren U, Sundqvist G. Cholesterol crystals as an etiological factor in non resolving chronic inflammation: an experimental study in guinea pigs. Eur J Oral Sci 1998;106:644650.

22. Yashima M, Ogura N, Abiko Y. Studies on cholesterol accumulation in radicular cyst fluid - origin of heat-stable cholesterol-binding protein. Int J Biochem 1990;22:165-169.

23. Nair PN, Sjögren U, Schumacher E, Sundqvist G. Radicular cyst affecting a root-filled human tooth: a long-term post-treatment follow-up. Int Endod J 1993;26:225-233.

24. Richardson J, Morgan P. Foam cell transformation in periapical lesions of endodontic origin. J Endod 1982;8:563-566.

25. Nair PN, Sjögren U, Krey G, Sundqvist G. Therapy-resistant foreign body giant cell granuloma at the periapex of a root-filled human tooth. J Endod 1990;16:589-595.

Received August 19, 2011

Accepted October 1, 2011 